\title{
Balanced Development of Piezoelectricity and Curie Temperature in KNN-BC-xBNH Lead-Free Ceramics
}

\author{
YUE WEN, ${ }^{1,2}$ GUIFEN FAN, ${ }^{1,2,4}$ MENGMENG HAO, ${ }^{1,2}$ \\ YANJONG WANG, ${ }^{1,2}$ XIN CHEN, ${ }^{1,2}$ QIANWEI ZHANG, ${ }^{3}$ \\ and WENZHONG LV ${ }^{1,2}$
}

\begin{abstract}
1.-School of Optical and Electronic Information, Huazhong University of Science and Technology, Wuhan 430074, People's Republic of China. 2.-Key Lab of Functional Materials for Electronic Information, MOE, Huazhong University of Science and Technology, Wuhan 430074, People's Republic of China. 3.-School of Metallurgy and Materials Engineering, Chongqing University of Science and Technology, University Town, Shapingba District, Chongqing 401331, People's Republic of China. 4._e-mail: fan_gf@mail.hust.edu.cn
\end{abstract}

In this work, $(0.996-\mathrm{x})\left(\mathrm{K}_{0.48} \mathrm{Na}_{0.52}\right) \mathrm{NbO}_{3}-0.004 \mathrm{BiCoO}_{3}-\mathrm{xBi}_{0.5} \mathrm{Na}_{0.5} \mathrm{HfO}_{3}(\mathrm{ab}-$ breviated as $\mathrm{KNN}-\mathrm{BC}-\mathrm{xBNH}$ ) lead-free ceramics were prepared by the conventional solid-state sintering method. The effects of $\mathrm{Bi}_{0.5} \mathrm{Na}_{0.5} \mathrm{HfO}_{3}$ content on the microstructure and piezoelectric properties of ceramic crystals were systematically studied. The results of x-ray diffraction (XRD) and temperature dependence of the dielectric constant showed that with the increase of $\mathrm{Bi}_{0.5}$ $\mathrm{Na}_{0.5} \mathrm{HfO}_{3}$ content, the rhombohedral-orthorhombic $\left(T_{\mathrm{R}-\mathrm{O}}\right)$ and orthorhombic-tetragonal $\left(T_{\mathrm{O}-\mathrm{T}}\right)$ phase-transition temperature gradually moved to the vicinity of room temperature. The KNN-BC-xBNH lead-free ceramics with $x=0.035$ exhibited optimal electrical properties of $d_{33} \sim 272 \mathrm{pC} / \mathrm{N}, k_{\mathrm{p}} \sim 0.47$, $P_{\mathrm{r}} \sim 25.63 \mu \mathrm{C} / \mathrm{cm}^{2}, E_{\mathrm{C}} \sim 13.31 \mathrm{kV} / \mathrm{cm}$, Curie temperature $T_{\mathrm{c}} \sim 333^{\circ} \mathrm{C}, S_{\max }$ $\sim 0.15 \%$ and $d_{33}^{*} \sim 358 \mathrm{pm} / \mathrm{V}$. These results suggest that the KNN-BC$0.035 \mathrm{BNH}$ ceramic is a promising ceramic system for industrial application.

Key words: Lead-free ceramics, curie temperature, piezoelectric properties, phase transition

\section{INTRODUCTION}

Piezoelectric materials, which can convert mechanical energy to electrical energy, have been widely used in electronic devices, such as sensors, actuators, filters, buzzers and so on. ${ }^{1-3}$ Lead-based materials, such as lead zirconate $\left[\mathrm{Pb}(\mathrm{Zr}, \mathrm{Ti}) \mathrm{O}_{3}, \mathrm{PZT}\right]-$ based materials have dominated current applications in the past few decades because of their high piezoelectric coefficient and Curie temperature. It is frustrating that lead-based piezoelectric ceramics contain 60 wt.\% lead, which seriously affects our health and endangers the environment. ${ }^{4}$ Therefore, it is urgent to develop lead-free piezoelectric

(Received July 10, 2019; accepted November 7, 2019; published online November 26, 2019) materials with excellent piezoelectric properties to replace lead-based piezoelectric materials. ${ }^{5}$

In the past few years, potassium-sodium niobate $(\mathrm{K}, \mathrm{Na}) \mathrm{NbO}_{3}(\mathrm{KNN})$ has been regarded as a potential candidate to replace lead-based piezoelectric materials because of its good electrical properties and a high Curie temperature $\left(T_{\mathrm{c}}\right){ }^{6-13}$ However, the polymorphic phase transition (PPT) in $\mathrm{KNN}$-based materials is different from the morphotropic phase boundaries (MPB) in PZT-based materials, and their electrical properties are related not only to composition but also to temperature. ${ }^{14}$ In addition, it is difficult to obtain high piezoelectric properties and Curie temperature simultaneously in $\mathrm{KNN}$ based ceramics. For example, Zheng et al. discovered a large $d_{33} \sim 460 \mathrm{pC} / \mathrm{N}$ in lead-free $0.96\left(\mathrm{~K}_{0.4}\right.$ $\left.\mathrm{Na}_{0.6}\right)\left(\mathrm{Nb}_{0.96} \mathrm{Sb}_{0.04}\right) \mathrm{O}_{3}-\mathrm{xBi}_{0.5} \mathrm{~K}_{0.5} \mathrm{Zr}_{0.9} \mathrm{Sn}_{0.1} \mathrm{O}_{3}$ ceramics, in which a relatively poor $T_{\mathrm{c}} \sim 246^{\circ} \mathrm{C}$ was observed. ${ }^{15}$ Beyond that, Wang et al. have reported 
a giant $\mathrm{d}_{33}$ of $425 \mathrm{pC} / \mathrm{N}$ but a relatively poor $\mathrm{T}_{\mathrm{c}} \sim 239^{\circ} \mathrm{C}$ in $0.9575\left(\mathrm{~K}_{0.48} \mathrm{Na}_{0.52}\right)\left(\mathrm{Nb}_{0.96} \mathrm{Sb}_{0.04}\right) \mathrm{O}_{3^{-}}$ $0.0425\left[\mathrm{Bi}_{0.5}\left(\mathrm{Na}_{0.7} \mathrm{Ag}_{0.3}\right)_{0.5}\right]_{0.90} \mathrm{Zn}_{0.10} \mathrm{ZrO}_{3}$ ceramics. $^{16}$

More recently, some studies have shown that bismuth-based compounds substituted for PZT can simultaneously achieve good electrical properties and high Curie temperature. ${ }^{17-20} \mathrm{BiScO}_{3}$ $\mathrm{Pb}(\mathrm{Zr}, \mathrm{Ti}) \mathrm{O}_{3},{ }^{21} \quad \mathrm{BiGaO}_{3}-\mathrm{PbTiO}_{3},{ }^{22} \quad \mathrm{BiAlO}_{3}$ $\mathrm{Pb}(\mathrm{Zr}, \mathrm{Ti}) \mathrm{O}_{3}$, ${ }^{23}$ and $\mathrm{Bi}\left(\mathrm{Mg}_{1 / 2} \mathrm{Ti}_{1 / 2}\right) \mathrm{O}_{3}-\mathrm{PbTiO}_{3}{ }^{24}$ are some interesting high-temperature piezoelectric materials. At the same time, bismuth-based compounds have also been reported to substitute for lead-free piezoelectric ceramics. For example, $\mathrm{Ma}$ et al. ${ }^{25}$ reported a large $d_{33}$ of $438 \mathrm{pC} / \mathrm{N}$ and a high $T_{\text {c }}$ of $320^{\circ} \mathrm{C}$ in $\mathrm{BiFeO}_{3}$-doped $\mathrm{KNN}$-based ceramics. Xing et al. ${ }^{26}$ have prepared $\mathrm{BiGaO}_{3}$ doped $\mathrm{KNN}$ based ceramics, and an excellent $d_{33} \sim 312 \mathrm{pC} / \mathrm{N}$ and a high $T_{\mathrm{c}} \sim 341^{\circ} \mathrm{C}$ were simultaneously obtained in this system. Outside of this, it was reported that a giant $d_{33} \sim 366 \mathrm{pC} / \mathrm{N}$ together with $T_{\mathrm{c}}$ of $335^{\circ} \mathrm{C}$ could be observed in $\mathrm{BiScO}_{3}$-doped KNN-based ceramics. ${ }^{27}$ As a result, we can draw conclusions from many reports that $\mathrm{KNN}$-based ceramics doping with $\mathrm{BiMO}_{3}$ (e.g., $\mathrm{Fe}, \mathrm{Ga}$ and $\mathrm{Sc}$ ) can realize a relatively giant $d_{33}$ together with a $T_{\mathrm{c}}$ value. In this work, the piezoelectric properties and phase transition in a $(0.996-\mathrm{x})\left(\mathrm{K}_{0.48} \mathrm{Na}_{0.52}\right) \mathrm{NbO}_{3}-$ $0.004 \mathrm{BiCoO}_{3}-\mathrm{xBi}_{0.5} \mathrm{Na}_{0.5} \mathrm{HfO}_{3}$ ceramic system will be studied, and the $\mathrm{BiCoO}_{3}$ is particularly used to equilibrate piezoelectric properties and Curie temperature.

\section{PROCEDURE}

In this work, we have successfully prepared a lead-free piezoelectric material system of $(0.996$ $\mathrm{x})\left(\mathrm{K}_{0.48} \mathrm{Na}_{0.52}\right) \mathrm{NbO}_{3}-0.004 \mathrm{BiCoO}_{3}-\mathrm{xBi}_{0.5} \mathrm{Na}_{0.5} \mathrm{HfO}_{3}$ (KNN-BC-xBNH, $x=0,0.01,0.02,0.03,0.035,0.04$, 0.045). Raw materials including $\mathrm{Na}_{2} \mathrm{CO}_{3}(99.8 \%)$, $\mathrm{K}_{2} \mathrm{CO}_{3}(99 \%), \mathrm{Nb}_{2} \mathrm{O}_{5}(99.99 \%), \mathrm{Bi}_{2} \mathrm{O}_{3}$ (99.999\%), $\mathrm{Co}_{2} \mathrm{O}_{3}(99 \%)$ and $\mathrm{HfO}_{2}(99.9 \%)$ were used to prepare this material system by the conventional solid-state sintering method. All powders were weighed with an electric balance and then were ball-milled for $8 \mathrm{~h}$ with alcohol, and then the dried powders were calcined at $850^{\circ} \mathrm{C}$ for $6 \mathrm{~h}$. After that, these calcined powders were ball-milled again for $8 \mathrm{~h}$ and were mixed with a binder of 5 wt.\% polyvinyl alcohol (PVA). These granulated powders were pressed into pellets with a diameter of $12 \mathrm{~mm}$ and a thickness of $1 \mathrm{~mm}$ under a pressure of $2 \mathrm{Mpa}$. The $\mathrm{KNN}-\mathrm{BC}-$ $\mathrm{xBNH}$ green samples were sintered at $1140-1180^{\circ} \mathrm{C}$ for $4 \mathrm{~h}$ in air, and the ceramics were pasted silver and fired at $550^{\circ} \mathrm{C}$ for $10 \mathrm{~min}$. At last, the ceramic samples were poled at room temperature in a silicon oil bath under a direct-current electric field of 3$4 \mathrm{kV} \mathrm{mm}^{-1}$.

The crystalline phases of the ceramics were characterized by x-ray diffraction (XRD) analysis (Shimadzu XRD7000, Japan) with $\mathrm{Cu} K \alpha$ radiation.
The surface microstructures were observed by scanning electron microscopy (SEM, JEOL, JSM-7600F, Japan). Dielectric properties were measured using an impedance analyzer (Agilent 4294A, Keysight Technologies, USA) and a high-temperature measurement system (VDMS-2000, Partulab, China) in the temperature range of $30-500^{\circ} \mathrm{C}$ and -100 $200^{\circ} \mathrm{C}$ at different frequencies. The piezoelectric constant $d_{33}$ was measured using a quasi-static $d_{33} \mathrm{~m}$ (ZJ-3A, Institute of Acoustics, Chinese Academy of Science, China) at $50 \mathrm{~Hz}$. In addition, we utilized a precision impedance analyzer (Agilent 4192A, USA) to measure the resonance, anti-resonance frequencies, and corresponding impedance to calculate the planar electromechanical coupling coefficient $k_{\mathrm{p}}$. The ferroelectric properties were determined using a ferroelectric testing system (Radiant Technologies, USA). The unipolar strainelectric (S-E) field of KNN-BC-xBNH ceramics was determined using a ferroelectric testing system (TF2000E, aixACCT, Germany).

\section{RESULTS AND DISCUSSION}

Figure 1a shows the XRD patterns of the KNNBC-xBNH ceramics with $0 \leq x \leq 0.045$ in the $2 \theta$ range of $20^{\circ}-70^{\circ}$. As shown in Fig. 1a, all components form a single perovskite structure without second phase generation. With the increase of $x$ content, the characteristic XRD diffraction peaks of ceramics at $45^{\circ}$ have changed, which indicates that a phase transition occurs. In order to better observe the process of phase transition, expanded XRD analysis was carried out in the $2 \theta$ range of $44^{\circ}-47^{\circ}$ and $64^{\circ}-68^{\circ}$, as Fig. $1 b$ and c shows. For a orthorhombic $(\mathrm{O})$ phase, the peak intensity on the left is higher than that on the right in the $2 \theta$ range of $44^{\circ}-47^{\circ}$, and the peak intensity on the right is higher than that on the left in the $2 \theta$ range of $64^{\circ}-$ $68^{\circ}$. Meanwhile, in the case of a tetragonal (T) phase, the peak intensity on the right is higher than that on the left in the $2 \theta$ range of $44^{\circ}-47^{\circ}$, and the peak intensity on the left is higher than that on the right in the $2 \theta$ range of $64^{\circ}-68^{\circ}$. From this result, it can be observed that with the increase of $\mathrm{BNH}$ content, the phase structure of the ceramics at room temperature gradually changed from orthorhombic (O) phase to tetragonal (T) phase. ${ }^{28}$ When $x=0.045$, the characteristic peak of ceramics becomes a single diffraction peak which may be possess a pseudocube phase.

To further confirm the crystal structure, we have measured the temperature dependent on the dielectric constant $\left(\varepsilon_{\mathrm{r}}-T\right)$ curves, as shown in Fig. 2. All samples were measured at $30-500^{\circ} \mathrm{C},-100-200^{\circ} \mathrm{C}$ and at $f=100 \mathrm{kHz}$. As seen in Fig. 2a, when $0<x<0.03$, the ceramic sample has two distinct dielectric constant change points in the range of room temperature to $500^{\circ} \mathrm{C}$ corresponding to the orthorhombic-to-tetragonal phase-transition temperature $\left(T_{\mathrm{O}-\mathrm{T}}\right)$ and the ferroelectric-to-paraelectric 

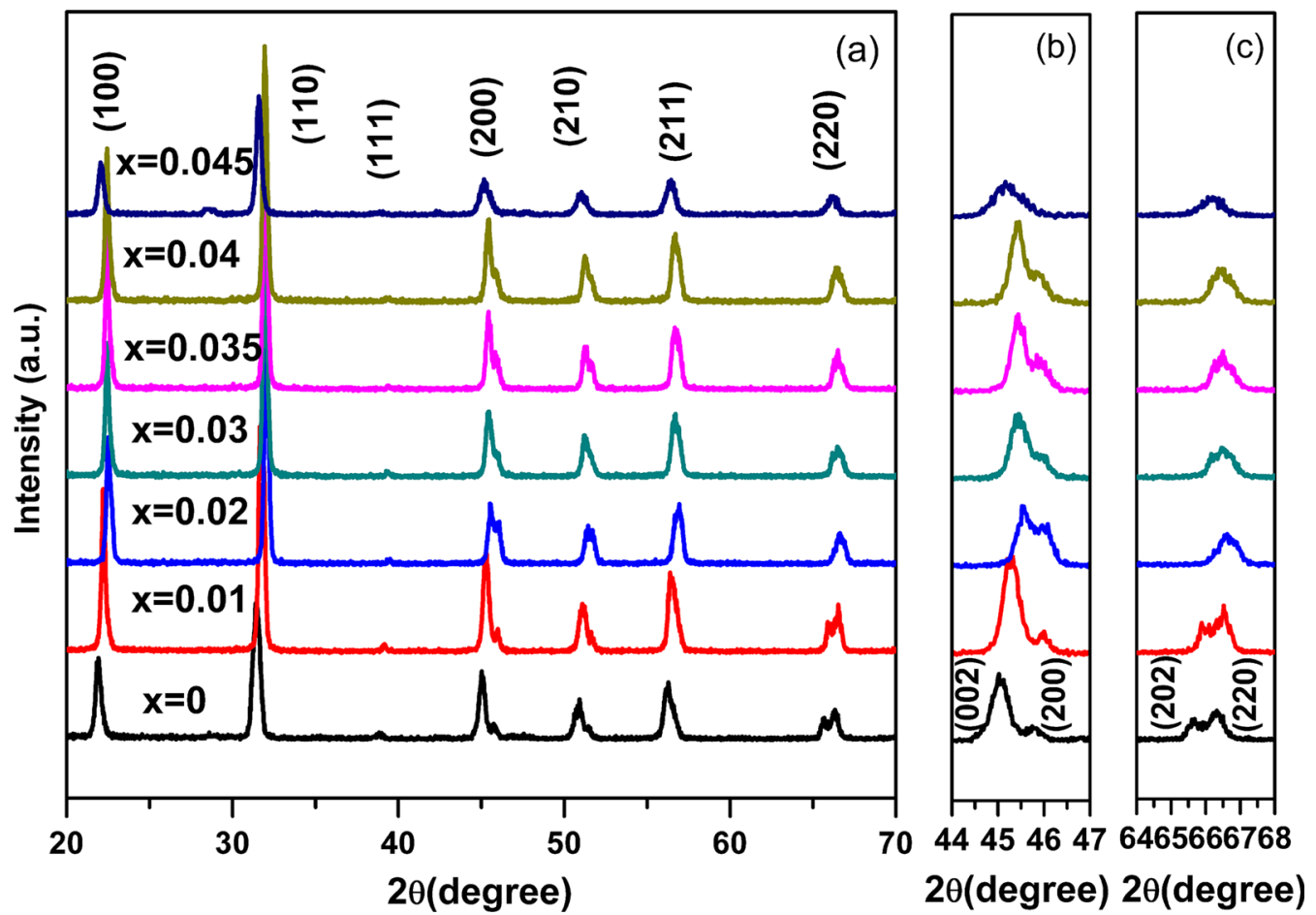

Fig. 1. (a) The XRD patterns of KNN-BC-XBNH lead-free piezoelectric ceramic, (b) expanded XRD patterns in the $2 \theta$ range of $44^{\circ}-47^{\circ}$ and (c) expanded XRD patterns in the $2 \theta$ range of $64^{\circ}-68^{\circ}$.

(a)

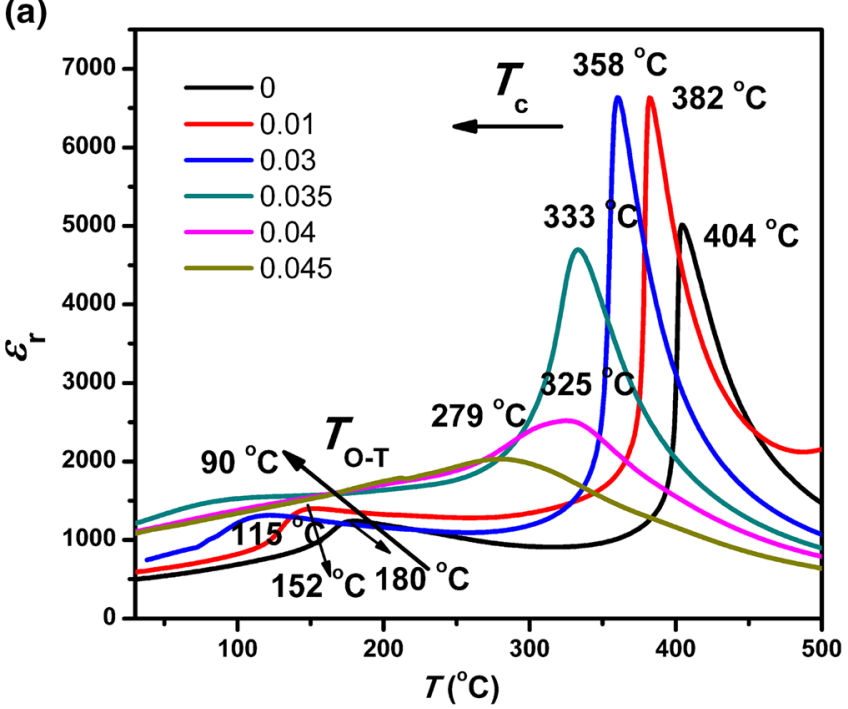

(b)

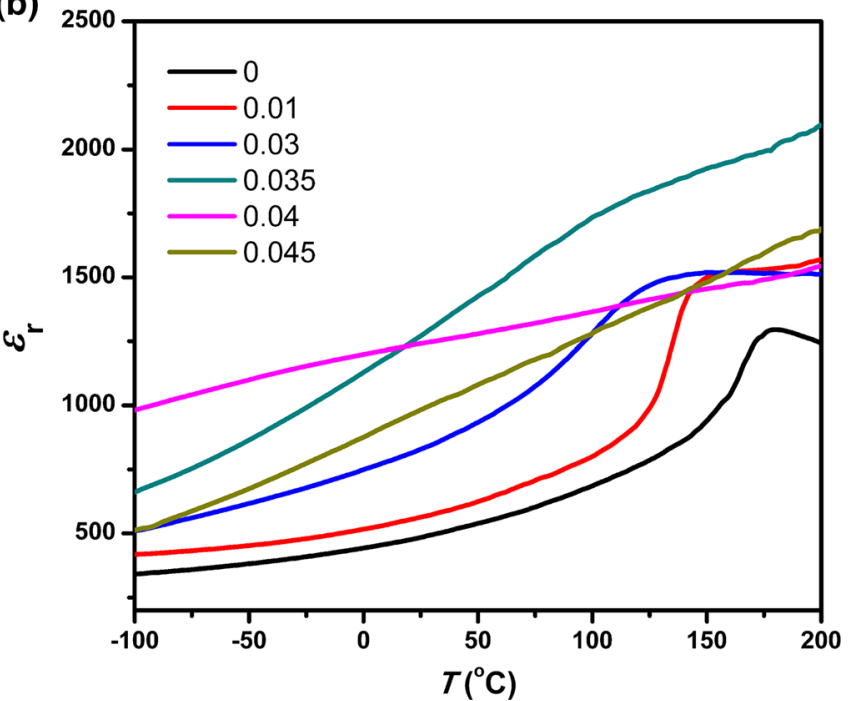

Fig. 2. Dielectric constants at $100 \mathrm{kHz}$ of $\mathrm{KNN}-\mathrm{BC}-\mathrm{xBNH}$ lead-free piezoelectric ceramics in the temperature range of (a) $30-500^{\circ} \mathrm{C}$ and (b) $-100-200^{\circ} \mathrm{C}$.

phase-transition temperature $\left(T_{\mathrm{c}}\right)$, respectively. Moreover, the orthogonal-to-tetragonal phase-transition temperatures are $180^{\circ} \mathrm{C}, 152^{\circ} \mathrm{C}$ and $115^{\circ} \mathrm{C}$. It shows that with the increase of $\mathrm{BNH}$ content, the tetragonal phase gradually moves to room temperature, which is consistent with the previous XRD results. For the sample of $x=0.035$, the low-temperature dielectric constant peak becomes relatively flat and is close to room temperature. For the samples of $x=0.04$ and $x=0.045$, the low- temperature dielectric constant peaks disappear completely. The Curie temperature $\left(T_{\mathrm{c}}\right)$ of ceramics decreases more obviously with the increase of $\mathrm{BNH}$ content; When $x=0.045$, the dielectric constant peak corresponding to Curie temperature exhibits a broadening effect, as reported by $\mathrm{Xu}$ et al. ${ }^{29} \mathrm{Com}-$ bining with the $\varepsilon_{r}-T$ curves at $-100-200^{\circ} \mathrm{C}$, as shown in Fig. 2b, the rhombohedral-to-orthorhombic ( $\mathrm{R}-\mathrm{O}$ ) phase-transition peaks below room temperature reported in the literature are not observed 

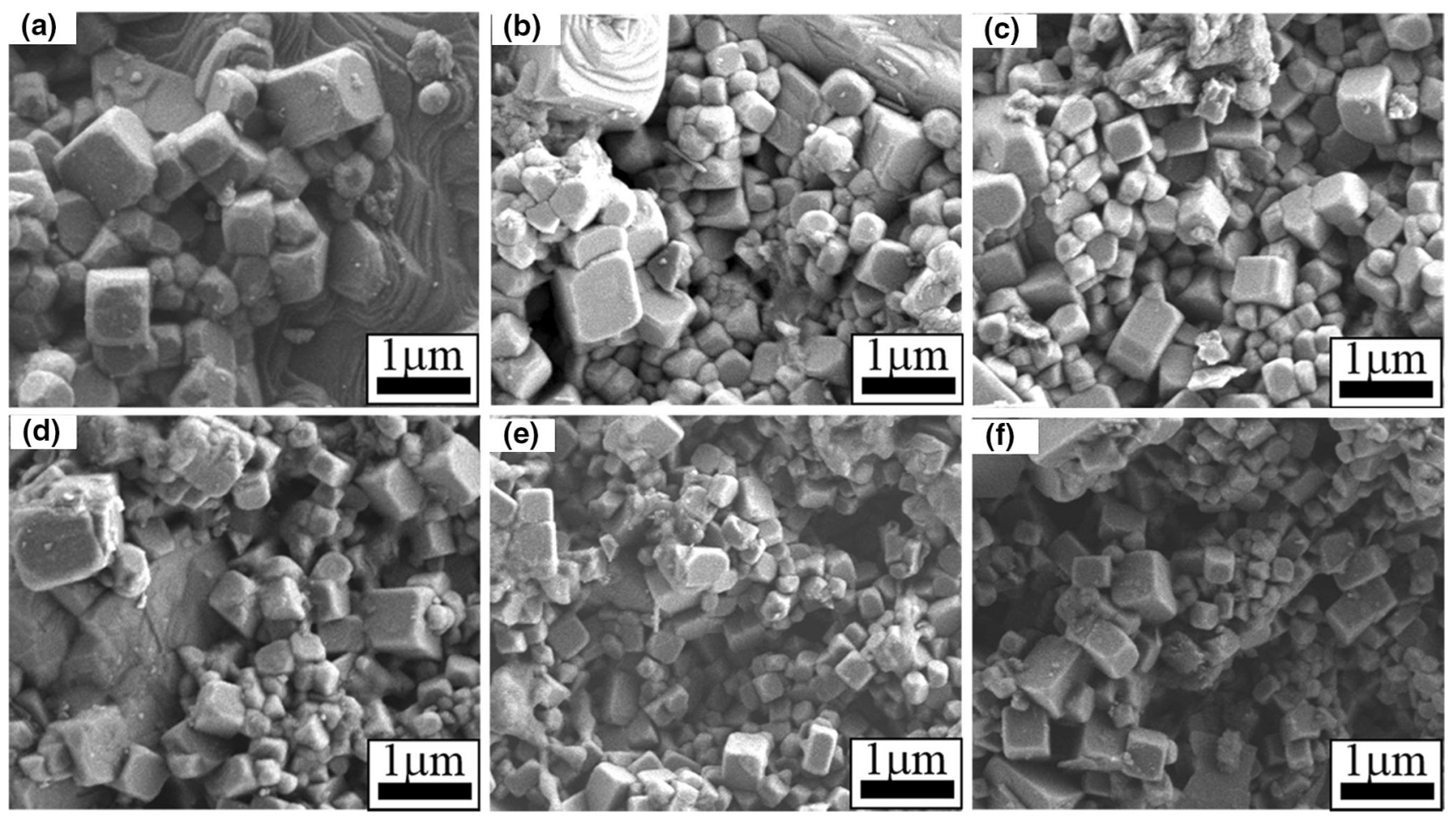

Fig. 3. SEM images of KNN-BC-xBNH lead-free piezoelectric ceramic: (a) $x=0.01$, (b) $x=0.02$, (c) $x=0.03$, (d) $x=0.035$, (e) $x=0.04$, (f) $x=0.045$.

in all samples. ${ }^{30}$ And according to the XRD result, for the sample of $x=0.045$, the ceramic possesses pseudo-cube phase, and the R-T and O-T phasetransition peaks in the $\varepsilon_{r}-T$ curve are not observed. This may be because the $\mathrm{R}-\mathrm{O}$ phase-transition temperature moves to room temperature with the increase of $\mathrm{BNH}$ content. Therefore, it can be inferred that the coexistence region of $\mathrm{R}-\mathrm{O}-\mathrm{T}$ phase transition exists in the range of $0.035 \leq x \leq 0.04$ for $\mathrm{KNN}-\mathrm{BC}-\mathrm{xBNH}$.

Figure 3 shows the SEM images of the surface of the KNN-BC-xBNH ceramic samples. One can see from Fig. 3 that all ceramic samples have rectangular-shaped particles and are dense. The grain size appears uniform, and most of the grain sizes are about $1 \mu \mathrm{m}$. It can also be observed that with the increase of $\mathrm{BNH}$ content, the grain size of ceramics decreases. Meanwhile, small grains are filled among large grains, which increases the density of ceramics, and this is also an important reason for the improvement of electrical properties. ${ }^{31}$ In the end, for the sample with $x=0.045$, the grain size is significantly reduced, which is about $0.2 \mu \mathrm{m}$. The reason is that the addition of $\mathrm{BNH}$ reduces the sintering activity of ceramics, or the sintering temperature will increase with the enhancement of $\mathrm{BNH}$ amount.

Figure 4 shows the density curve of ceramics with different $\mathrm{BNH}$ doping amounts. It can be seen that as the amount of BNH doping increases, the density of ceramics increases first and then decreases.

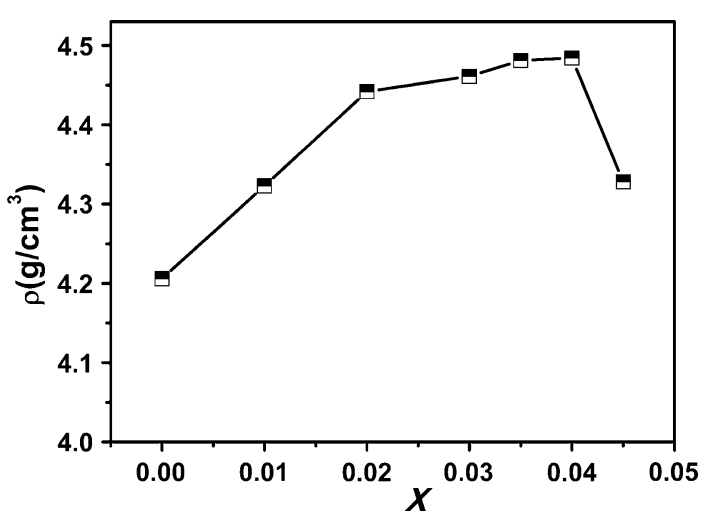

Fig. 4. Density curve of the KNN-BC-xBNH lead-free piezoelectric ceramic as a function of $\mathrm{BNH}$ content.

When $x=0.04$, the maximum density is $4.48 \mathrm{~g} /$ $\mathrm{cm}^{3}$. Therefore, proper BNH addition helps to improve the density of ceramics. For the samples with excess $\mathrm{BNH}$, the density of the ceramic sample decreases, which is mainly due to the low sintering temperature and the lack of densification of ceramics.

Figure 5 shows the polarization-electric field (PE) hysteresis loops of the KNN-BC-xBNH ceramic samples measured at $f=10 \mathrm{~Hz}$ and room temperature. The ceramic samples have saturated hysteresis loops, indicating that $\mathrm{KNN}-\mathrm{BC}-\mathrm{xBNH}$ ceramics are good ferroelectrics. We can find that after doping $\mathrm{BNH}$ in $\mathrm{KNN}-\mathrm{BC}-\mathrm{xBNH}$ ceramic, the 
(a)

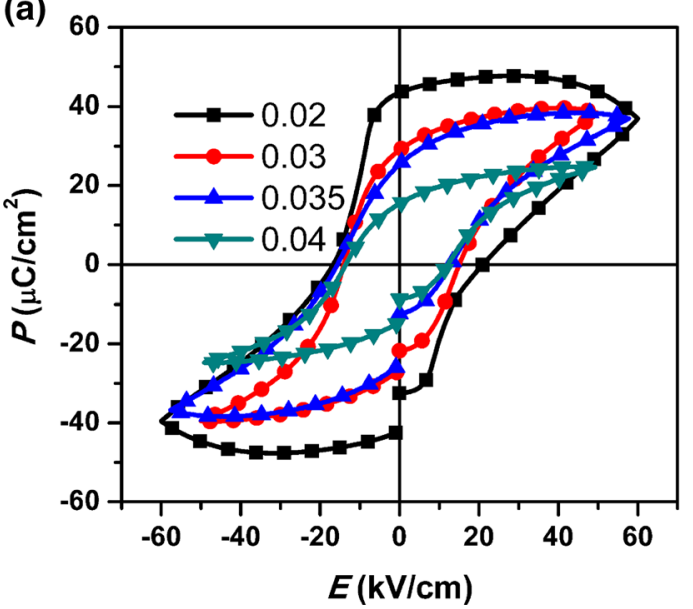

(b)

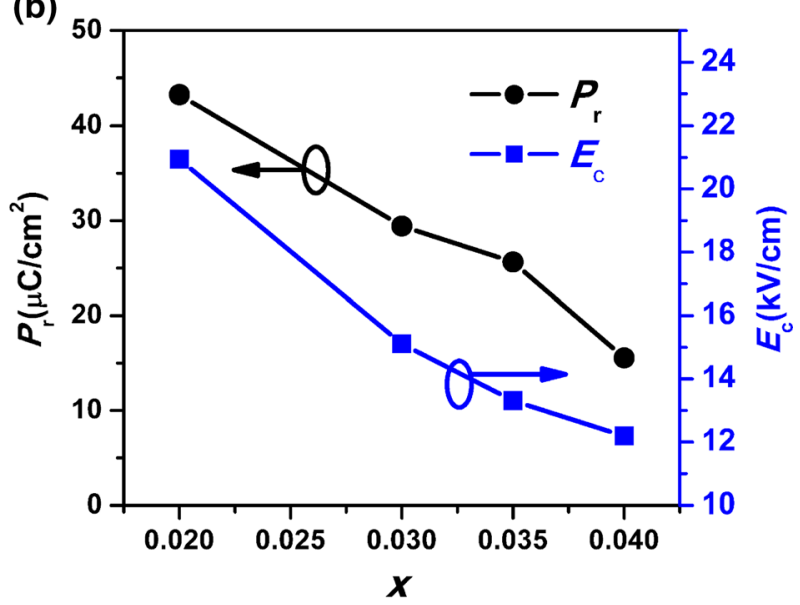

Fig. 5. (a) P-E loops of the KNN-BC-xBNH lead-free piezoelectric ceramics as a function of BNH content; (b) $P_{\mathrm{r}}$ and $E_{\mathrm{C}}$ of this ceramic.

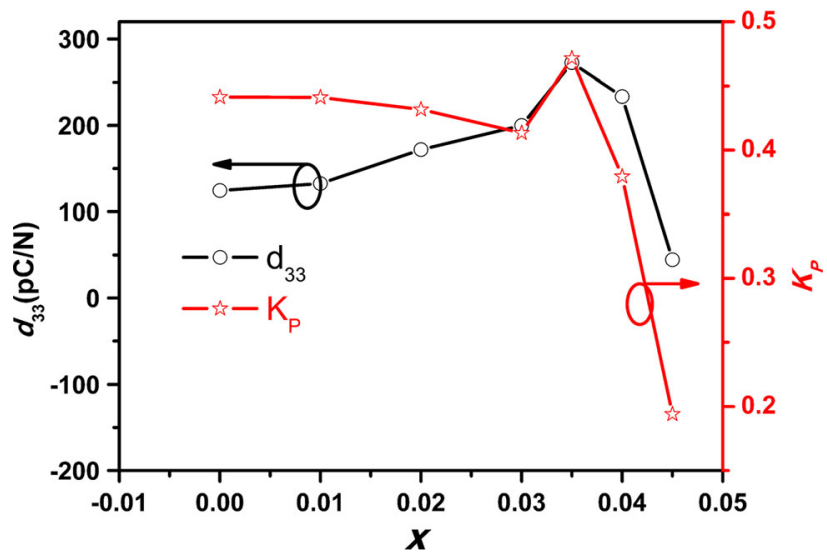

Fig. 6. Piezoelectric properties of KNN-BC-xBNH lead-free piezoelectric ceramics.

remnant polarization $\left(P_{\mathrm{r}}\right)$ and the coercive field $\left(E_{\mathrm{c}}\right)$ were simultaneously decreased gradually, which indicates that ferroelectrics of samples are weakened gradually. According to the curves of $\varepsilon_{\mathrm{r}}-T$, with the increase of $\mathrm{BNH}$ content, the decrease of dielectric constant value for Curie peak also illustrates that the ferroelectric is weakening too. In addition, the sample with $x=0.035$ had correspondingly large remnant polarization $\left(P_{\mathrm{r}}\right)$ of $25.63 \mu \mathrm{C} /$ $\mathrm{cm}^{2}$ and a correspondingly small coercive field $\left(E_{\mathrm{c}}\right)$ of $13.31 \mathrm{kV} / \mathrm{cm}$.

Figure 6 illustrates the piezoelectric properties of $\mathrm{KNN}-\mathrm{BC}$-xBNH lead-free piezoelectric ceramics. It is obvious that the dopant of $\mathrm{BNH}$ contributes to the improvement of piezoelectric properties of ceramics. With the increase of $\mathrm{x}$, their $d_{33}$ and $k_{\mathrm{p}}$ values show a similar trend. The sample with $x=0.035$ possesses optimum piezoelectric properties $\left(d_{33} \sim 272\right.$
$\mathrm{pC} / \mathrm{N}$ and $\left.k_{\mathrm{p}} \sim 0.47\right)$. The excellent piezoelectric properties of the KNN-BC-xBNH ceramics can be elucidated as follows: first of all, combining with the XRD and $\varepsilon_{\mathrm{r}}-T$ curves, we can find that R-O-T phase transition exists in the range of $0.035 \leq x \leq 0.04$ for KNN-BC-xBNH, which makes the domain switching easier; ${ }^{32}$ secondly, from the SEM images and density curve, when $0.035 \leq x \leq 0.04$, the grain size is relatively uniform and the density is relatively large, which is beneficial to improving the piezoelectric performance.

Figure 7 show the S-E unipolar strain curves of the KNN-BC-xBNH ceramic samples measured at $f=10 \mathrm{~Hz}$ and room temperature. It is obvious that the ceramics samples possess a larger unipolar strain in the phase boundary regions, indicating that phase transition can availably increasing piezoelectric properties of $\mathrm{KNN}-\mathrm{BC}-\mathrm{xBNH}$ ceramics sample, as reported by $\mathrm{Wu}$ et al. ${ }^{33}$ Finally, the ceramics sample with $x=0.035$ has the optimum unipolar strain value $S_{\max } \sim 0.15 \%$ and $d_{33}^{*} \sim 358$ $\mathrm{pm} / \mathrm{V}$.

\section{CONCLUSIONS}

In this work, the phase transition, microstructure and electrical properties of a KNN-BC-xBNH ceramics system were researched. The R-O-T boundary could be discovered in the samples with $x=0.03-0.04$. The grain size evolution demonstrated that a certain amount of BNH would lead to abnormal grain growth, which is conducive to the improvement of densities of $\mathrm{KNN}$-based lead-free piezoelectric ceramics. The samples with $x=0.035$ possess the optimum piezoelectric properties: $d_{33}$ $272 \mathrm{pC} / \mathrm{N}, k_{\mathrm{p}} \sim 0.471, T_{\mathrm{c}} \sim 333^{\circ} \mathrm{C}, P_{\mathrm{r}} \sim 25.63 \mu \mathrm{C} /$ 

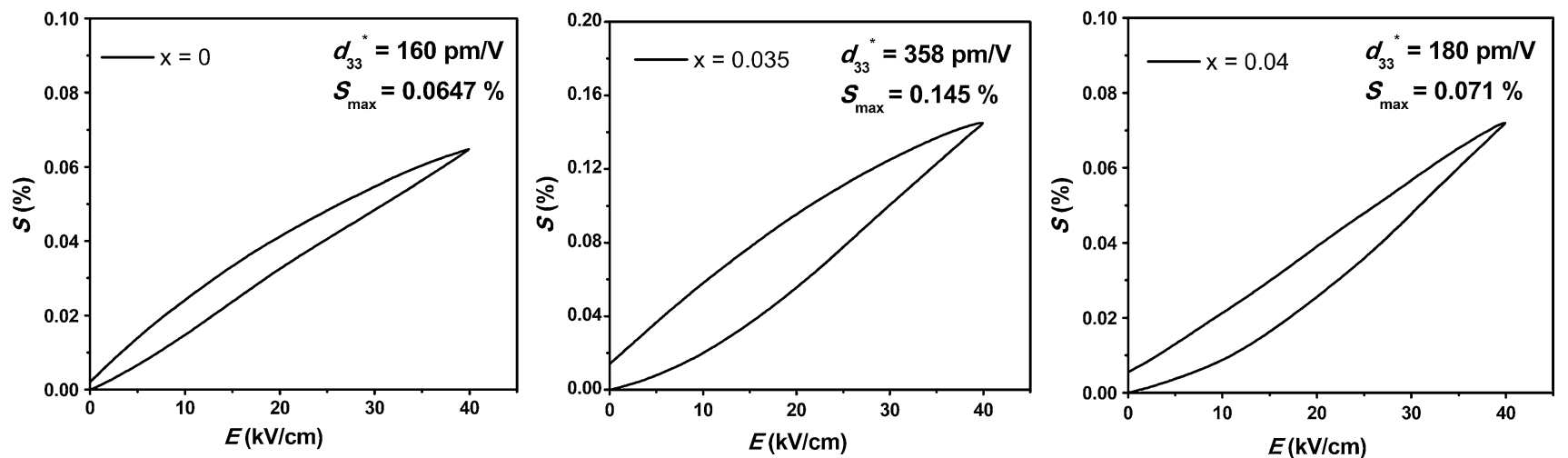

Fig. 7. Unipolar strain-electric (S-E) field curves of the KNN-BC-xBNH lead-free piezoelectric ceramics at a frequency of $10 \mathrm{~Hz}$.

$\mathrm{cm}^{2}, \quad E_{\mathrm{C}} \sim 13.31 \mathrm{kV} / \mathrm{cm}, \quad S_{\max } \sim 0.145 \%$ and $d_{33}^{*}$ $358 \mathrm{pm} / \mathrm{V}$.

\section{ACKNOWLEDGMENTS}

This work was supported by International Scientific and Technological Innovation Cooperation Key Projects for National Key R\&D Program of China (no. 2016YFE0203900), National Key R\&D Program of China (no. 2018YFC0116100), and Nature Science Foundation of HuBei Province of China (no. 2018CFB771). The authors thank the Analytical and Testing Center of the Huazhong University of Science.

\section{REFERENCES}

1. E. Aksel and J.L. Jones, Sensors 10, 1935 (2010).

2. H. P. Löbl, M. Klee, C. Metzmacher, W. Brand, F. Van Straten, In IEEE Ultrasonics Symposium. (2001). pp. 807811.

3. J. Rödel, W. Jo, K.T.P. Seifert, E. Anton, T. Granzow, and D. Damjanovic, J. Am. Ceram. Soc. 92, 1153 (2010).

4. T. Zheng, J.G. Wu, D.Q. Xiao, and J.G. Zhu, Prog. Mater Sci. 98,552 (2018).

5. T.R. Shrout, S. Jun, and J. Zhang, J. Electroceram. 19, 111 (2007).

6. F.Z. Yao, K. Wang, W. Jo, K.G. Webber, T.P. Comyn, J.X. Ding, B. Xu, L.Q. Cheng, M.P. Zheng, Y.D. Hou, and J.F. Li, Adv. Funct. Mater. 26, 1217 (2016).

7. X. Lv, J.G. Wu, J.G. Zhu, D.Q. Xiao, and X.X. Zhang, J. Eur. Ceram. Soc. 38, 38 (2018).

8. Z.Y. Cen, Y.C. Zhen, W. Feng, P.Y. Zhao, L.L. Chen, X.H. Wang, and L.T. Li, J. Eur. Ceram. Soc. 38, 3136 (2018).

9. Z.Y. Cen, Y. Yu, P.Y. Zhao, L.L. Chen, C.Q. Zhu, L.T. Li, and X.H. Wang, J. Mater. Chem. C. 7, 1379 (2019).

10. T. Zheng and J.G. Wu, ACS Appl. Mater. Inter. 8, 9242 (2016).

11. T. Zheng, J.G. Wu, D.Q. Xiao, J.G. Zhu, X.J. Wang, and X.J. Lou, J. Mater. Chem. A 3, 1868 (2015).

12. J.G. Wu, RSC Adv. 4, 53490 (2014).

13. T. Zheng, J.G. Wu, D.Q. Xiao, J.G. Zhu, X.J. Wang, and X.J. Lou, ACS Appl. Mater. Inter. 7, 20332 (2015).

14. F.Z. Yao, J. Glaum, K. Wang, W. Jo, J. Rödel, and J.F. Li, Appl. Phys. Lett. 103, 84 (2013).
15. H. Tao, J.G. Wu, T. Zheng, X.J. Wang, and X.J. Lou, J. Appl. Phys. 118, 84 (2015).

16. Y.Y. Wang, L. Hu, Q.L. Zhang, and H. Yang, Dalton Trans. 44, 13688 (2015).

17. T. Leist, W. Jo, T. Comyn, A. Bell, and J. Rödel, Jpn. J. Appl. Phys. 48, 120205 (2009).

18. J.G. Wu, H.D. Shi, T.L. Zhao, Y. Yu, and S.X. Dong, Adv. Funct. Mater. 26, 7186 (2016).

19. W. Zhang, M.M. Yang, X. Liang, H.W. Zheng, Y. Wang, W.X Gao, G.L. Yuan, W.F. Zhang, X.G. Li, H.S. Luo, and R.K. Zhang, Nano Energy 18, 315 (2015).

20. N.G. Luo, S.J. Zhang, Q. Li, Q.F. Yan, W.H. He, Y.L. Zhang, and T.R. Shrout, Appl. Phys. Lett. 104, 182911 (2014).

21. L.P. Kong, G. Liu, S.J. Zhang, and W.G. Yang, Appl. Phys. Lett. 106, 1804 (2015)

22. J.R. Cheng, W.Y. Zhu, N. Li, and L.E. Cross, Mater. Lett. 57, 2090 (2003).

23. N. Tawichai, T. Tunkasiri, S. Eitssayeam, K. Pengpat, and G. Rujijanagul, Phase Transit. 83, 994 (2010).

24. Q. Zhang, Z.R. Li, F. Li, Z. Xu, and X. Yao, J. Am. Ceram. Soc. 93, 3330 (2010).

25. J. Ma, B. Wu, W.J. Wu, and M. Chen, J. Mater. Sci. Mater. Electron. 28, 4458 (2017).

26. J. Xing, Z. Tan, J. Yuan, L.M. Jiang, Q. Chen, J.G. Wu, W. Zhang, D.Q. Xiao, and J.G. Zhu, RSC Adv. 6, 57210 (2016).

27. X.J. Cheng, J.G. Wu, X.J. Lou, X.J. Wang, X.P. Wang, D.Q. Xiao, and J.G. Zhu, ACS Appl. Mater. Inter. 6, 750 (2014).

28. F. Rubio-Marcos, P. Marchet, T. Merle-Méjean, and J.F. Fernandez, Mater. Chem. Phys. 123, 91 (2010).

29. D.D. Xue, Y.Y. Liu, M. Shi, P. Wang, L.Y. Zhang, G. Liu, Z.Q. Chen, and Y. Chen, J. Mater. Sci. Mater. Electron. 29, 2072 (2018).

30. X. Lv, J.G. Wu, S.A. Yang, D.Q. Xiao, and J.G. Zhu, ACS Appl. Mater. Inter. 8, 18943 (2016).

31. X. Lv, J.G. Wu, S. Yang, D.Q. Xiao, and J.G. Zhu, ACS Appl Mater. Iterfa. 8, 18943 (2016).

32. T. Zheng, H.J. Wu, Y. Yuan, X. Lv, Q. Li, T.L. Men, C.L. Zhao, D.Q. Xiao, J.G. Wu, K. Wang, J.F. Li, Y.L. Zhao, J.G. Zhu, and S.J. Pennycook, Energy Environ. Sci. 10, 528 (2017).

33. J.G. Wu, D.Q. Xiao, and J.G. Zhu, J. Mater. Sci. Mater. Electron. 26, 9297 (2015).

Publisher's Note Springer Nature remains neutral with regard to jurisdictional claims in published maps and institutional affiliations. 